ÊESTI NSV TEADUSTE AKADEEMIA TOIMETISED. KEEMIA

ИЗВЕСТИЯ АКАДЕМИИ НАУК ЭСТОНСКОП ССР. ХИМИЯ

PROCEEDINGS OF THE ACADEMY OF SCIENCES OF THE ESTONIAN SSR. CHEMISTRY

$1987,36,2$

удК 547.313

Эльви МУКС

\title{
СОПОСТАВЛЕНИЕ РЕАКЦИИ ЭЛЕКТРОФИЛЬНОГО ПРИСОЕ- ДИНЕНИЯ. КОНКУРИРУЮЩИЕ НАПРАВЛЕНИЯ, ОПРЕДЕЛЯЕМЫЕ СТРОЕНИЕМ АЛКЕНА
}

\author{
(Представил К. Лээтс)
}

При реакциях электрофильного присоединения к алкенам наряду с нормальными продуктами, в соответствии с правилом Марковникова, часто образуются и нерегулярные. Закономерностям образования побочных продуктов в зависимости от строения алкена внимания почти не уделялось, за исключением $\left[{ }^{1-5}\right]$. В настоящем обзоре объектом рассмотрения являются реакции присоединения галогеносодержащих электрофильных реагентов к простым алкенам в малополярных средах. При этом значительное внимание обращено на ионно-каталитическое присоединение алкилгалогенидов к алкенам (катионная теломеризация) ["]. Присоединение к алкенам галогенопроизводных различного строения и активности часто приводит к сложным смесям аддуктов - изомерным, дегидрогалогенированным и циклическим. Сопоставление по составу продуктов катионной теломеризации алкенов и продуктов катионной полимеризации и присоединения галогенов и галогеноводородов позволило сделать некоторые выводы о влиянии химического строения алкена на конкурирующие направления присоединения.

Механизм электрофильного присоединения к алкенам интенсивно изучается. Наряду с традиционным ионным типом предложены более сложные схемы реакции. Общим для них можно считать то, что лимитирующей стадии реакции предшествуют равновесные бимолекулярные взаимодействия донорно-акцепторного типа между компонентами реагирующей системы. В последние годы механизмы такого типа предложены для ионного присоединения галогенов $\left[{ }^{7-10}\right]$, галогеноводородов $\left[{ }^{9-11}\right]$, алкилгалогенидов $\left[{ }^{12}\right]$ и других реагентов $[7,10]$.

Сложными и до сих пор не разрешенными остаются вопросы о химическом строении активных интермедиатов и о переходных состояниях при электрофильном присоединении к алкенам. Однако основные направления образования тех или других конечных продуктов присоединения можно установить на основе химического строения возможных катионных интермедиатов, что и было проведено в настоящей работе.

Рассмотрим три группы алкенов.

1. $\alpha$-Разветвленные алкены (изоалкены) характеризуются высокой реакционной способностью во всех реакциях электрофильного присоединения $[5,13,14]$. В случае изоалкенов наряду с нормальными продуктами присоединения (A) часто образуются и дегидрогалогенированные $\left(\mathrm{Б}_{i}\right)$ (табл. 1 и 2). Например, при ионном хлорировании изоалкенов основными продуктами являются ненасыщенные монохлориды аллильного типа $\left(\mathrm{Б}_{1}, \mathrm{~b}_{2}\right)$ и, кроме того, продукты присоединения освободившегося галогеноводорода к исходному алкену (В) [2]. Образовавшиеся аллильные хлориды нередко называют продуктами замещения, хотя более правильно называть их продуктами перераспределения галогеноводорода. При этом главную роль играет химическое строение алкена, которое опреде- 


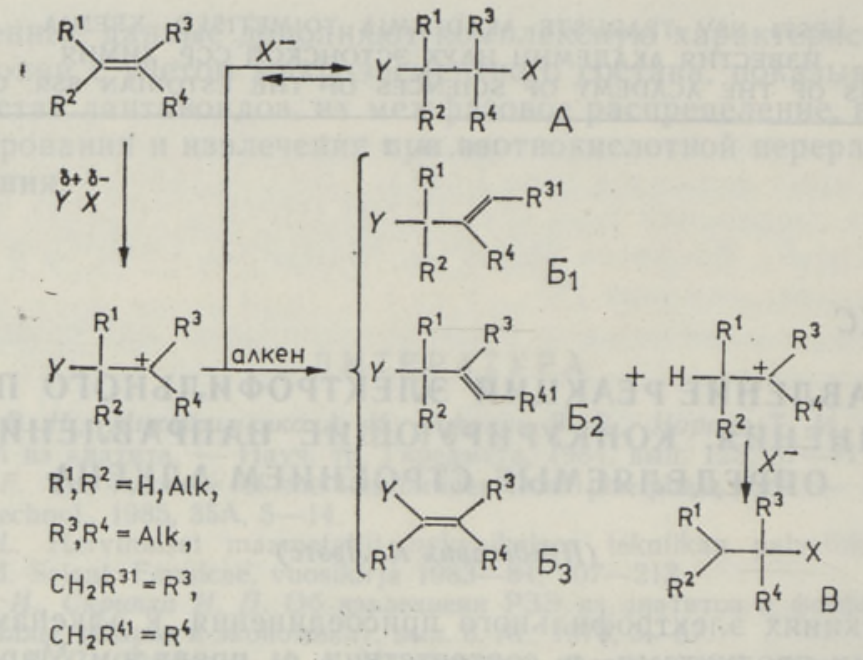

ляет строение интермедиата (как донора протона) и относительные скорости побочной и основной реакций. Несмотря на то, что реакционная способность $\beta$-хлорзамещенных изоалкенов на несколько порядков ниже, чем незамещенных, по степени перераспределения $\mathrm{HCl}$ при ионном хлорировании и катионной теломеризации (табл. 1 и 2) эти алкены близки. Это показывает, что внедрение заместителей в молекулу изоалкена сопровождается изменением скоростей основной и побочной реакций в одном направлении. Таким образом, степень перераспределения галогеноводорода определяется не только реакционной способностью алкена, как это допущено ранее $\left[{ }^{38}\right]$, но и количеством в нем $\beta$-водородных атомов. С другой стороны, от химического характера электрофильного реагента $У X$ значительно зависит количество побочных продуктов. Например, в случае ионного присоединения $\mathrm{Cl}_{2}\left[{ }^{5,15}, \mathrm{ClOH}\left[{ }^{39}\right]\right.$ или $\mathrm{ClOC}\left(\mathrm{CH}_{3}\right)_{3}$ $[40,41]$ к изоалкенам основными являются продукты элиминирования $\mathrm{H} X$ с образованием $\mathrm{b}_{1}$ и $\mathrm{b}_{2}(80-99 \%)$. А ионное присоединение $\mathrm{Br}_{2}$ дает в несколько раз меньшее количество продуктов с отщеплением $\mathrm{HBr}\left[{ }^{3,42}\right]$. При катионной теломеризации изоалкенов с алкилгалогенидами (R $X$ ) содержание нормального продукта (A) уменьшается (от 95 до 0\%) при понижении реакционной способности телогена $\mathrm{R} X$ (от 2-хлор-3-пентена до 1-хлор-2-пропена) $\left[{ }^{2}\right]$. Особенности катионной теломеризации изоалкенов более обстоятельно обсуждены в $\left[{ }^{2,43}\right]$.

Высокой степени катионной полимеризации изоалкенов можно достичь только при низких температурах [44]. Объясняется это малой скоростью роста цепи, а также легкостью передачи цепи из-за переноса протона в алкен.

Таблица 1

Относительный выход дегидрохлорированных аддуктов $\left(\mathbf{6}_{1}+\mathbf{G}_{2}\right)$ при хлорировании изоалкенов (I) [5] и $\beta$-хлорзамещенных изоалкенов (II) $[15-17]$ и их относительная реакционная способность при бромировании [14]

\begin{tabular}{|c|c|c|c|c|}
\hline Алкен I & $\begin{array}{c}\text { Выход } \\
\mathrm{B}_{1}+\mathrm{B}_{2} \\
\%\end{array}$ & Алкен II & $\begin{array}{c}\text { Выход } \\
\mathrm{b}_{1}+\mathrm{B}_{2} \\
\%\end{array}$ & $\frac{\kappa_{\text {алкен I }}}{\kappa_{\text {алкен II }}}$ \\
\hline $\begin{array}{l}\mathrm{CH}_{2}=\mathrm{C}\left(\mathrm{CH}_{3}\right)_{2} \\
\mathrm{CH}_{2}=\mathrm{C}\left(\mathrm{CH}_{3}\right) \mathrm{CH}_{2} \mathrm{CH}_{3} \\
\mathrm{CH}_{3} \mathrm{CH}=\mathrm{C}\left(\mathrm{CH}_{3}\right)_{2}\end{array}$ & $\begin{array}{l}87 \\
95 \\
85,5\end{array}$ & $\begin{array}{l}\mathrm{CH}_{2}=\mathrm{C}\left(\mathrm{CH}_{3}\right) \mathrm{CH}_{2} \mathrm{Cl} \\
\mathrm{CH}_{2}=\mathrm{C}\left(\mathrm{CH}_{3}\right) \mathrm{CHClCH}_{3} \\
\mathrm{CH}_{2} \mathrm{ClCH}=\mathrm{C}\left(\mathrm{CH}_{3}\right)_{2}\end{array}$ & $\begin{array}{r}80 \\
65 \\
100\end{array}$ & $\begin{array}{l}4,6 \cdot 10^{3} \\
4,4 \cdot 10^{3}\end{array}$ \\
\hline
\end{tabular}


Относительное содержание аддуктов присоединения $У X$ к алкенам $\mathrm{R}^{1} \mathrm{R}^{2} \mathrm{C}=\mathrm{CR}^{3} \mathrm{R}^{4}$, где $\mathrm{R}^{4}$ может быть $\mathrm{CR}^{5} \mathrm{R}^{6} \mathrm{R}^{7}$

\begin{tabular}{|c|c|c|c|c|c|c|}
\hline \multirow{2}{*}{$\underset{y-X}{y-X}$} & \multirow{2}{*}{$\begin{array}{c}\text { Катали- } \\
\text { затор }\end{array}$} & \multirow{2}{*}{ 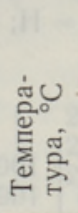 } & \multirow{2}{*}{ 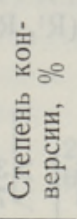 } & \multicolumn{2}{|c|}{$\begin{array}{c}\text { Относительное содержание } \\
\text { низших аддуктов, \% } \\
\text { (в скобках - выход, \%) }\end{array}$} & \multirow{2}{*}{ J } \\
\hline & & & & A & $\mid \begin{array}{c}Б_{i}, \text { В, } \Gamma_{i}, \text { Д } \\
\text { (см. схемы) и др.* }\end{array}$ & \\
\hline 1 & 2 & 3 & 4 & 5 & 6 & 7 \\
\hline
\end{tabular}

$$
\rangle=\left\langle\quad\left(R^{1}, R^{2}, R^{3}, R^{4}=\mathrm{CH}_{3}\right)\right.
$$

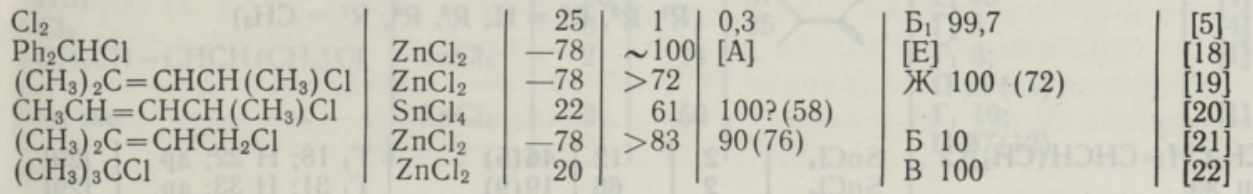

$\mathrm{Cl}_{2}$

$\mathrm{Cl}_{2} \mathrm{CH}_{3} \mathrm{OCH}_{2} \mathrm{Cl}$

$\mathrm{CH}_{3} \mathrm{CH}=\mathrm{CHCH}\left(\mathrm{CH}_{3}\right) \mathrm{Cl}$ $\mathrm{CH}_{3} \mathrm{CH}=\mathrm{C}\left(\mathrm{CH}_{3}\right) \mathrm{CH}_{2} \mathrm{Cl}$ $\mathrm{CH}_{2}=\mathrm{CHCH}_{2} \mathrm{Cl}$ $\mathrm{CH}_{3} \mathrm{COCl}$

$\mathrm{Cl}_{2}$
$\mathrm{Cl}_{2}$
$\mathrm{CH}_{3} \mathrm{OCH}_{2} \mathrm{Cl}$
$\mathrm{Ph}_{3} \mathrm{CCl}$

$\mathrm{Ph}_{2} \mathrm{CHCl}$

$\left(\mathrm{CH}_{3}\right)_{2} \mathrm{C}=\mathrm{CHC}\left(\mathrm{CH}_{3}\right)_{2} \mathrm{Cl}$ $\mathrm{CH}_{3} \mathrm{CH}=\mathrm{CHCH}\left(\mathrm{CH}_{3}\right) \mathrm{Cl}$ он же

\begin{tabular}{l|r|r|l} 
& 25 & 1 & 14,5 \\
$\mathrm{HgCl}_{2}$ & -12 & $>50$ & 12 \\
$\mathrm{SnCl}_{4}$ & 20 & $>40$ & $74(40)$ \\
$\mathrm{SnCl}_{4}$ & 23 & 79 & $94(73)$ \\
$\mathrm{SnCl}_{4}$ & 23 & 46 & $38(7)$ \\
$\mathrm{EtAlCl}_{2}$ & 48 & \\
& $\sim 10$ & $>66$ & $20(13)$
\end{tabular}
$=\left\langle\quad\left(\mathrm{R}^{1}, \mathrm{R}^{2}=\mathrm{H} ; \mathrm{R}^{3}, \mathrm{R}^{4}=\mathrm{CH}_{3}\right)\right.$

\begin{tabular}{l|c|c|l} 
& -9 & 1 & 13 \\
& 0 & $\sim 100$ & 13,5 \\
$\mathrm{HgCl}_{2}$ & 20 & $>60$ & $86(60)$ \\
$\mathrm{ZnCl}_{2}$ & 0 & 90 & \\
& & & \\
$\mathrm{ZnCl}_{2}$ & -78 & $>97$ & $100(97)$ \\
$\mathrm{ZnCl}_{2}$ & -78 & $>79$ & $100(79)$ \\
$\mathrm{ZnCl}_{2}$ & -78 & $>76$ & $100(76)$ \\
$\mathrm{SnCl}_{4}$ & 2 & 60 & $100(57)$
\end{tabular}

$\mathrm{b}_{1} 87$ $\mathrm{B}_{1} 84 ; \mathrm{b}_{3} 2,5 ;[\mathrm{B}]$ [Б]; В 14 Б, 16; 3 41 (21); И 43

$\mathrm{B}_{1} 85,5$
$\mathrm{~B}_{1} 82 ;[\mathrm{B}]$
$[$ Б]; B 26
Б $5 ;[$ B]
Б $52 ;[\mathrm{B}]$
Б $100(27) ;[\mathrm{B}]$
Б $_{1} 80$

\section{[5] $[26]$

$$
\mathrm{Cl}=\left\langle\left(\mathrm{R}^{1}=\mathrm{H} ; \mathrm{R}^{2}=\mathrm{CH}_{2} \mathrm{Cl} ; \mathrm{R}^{3}, \mathrm{R}^{4}=\mathrm{CH}_{3}\right)\right.
$$

$\mathrm{Cl}_{2}$

$\mathrm{CH}_{3} \mathrm{OCH}_{2} \mathrm{Cl}$

$\mathrm{C}_{2} \mathrm{H}_{5} \mathrm{OCH}_{2} \mathrm{Cl}$

$\mathrm{CH}_{3} \mathrm{CH}=\mathrm{CHCH}\left(\mathrm{CH}_{3}\right) \mathrm{Cl}$

$\left(\mathrm{CH}_{3}\right)_{2} \mathrm{C}=\mathrm{CHCH}_{2} \mathrm{Cl}$

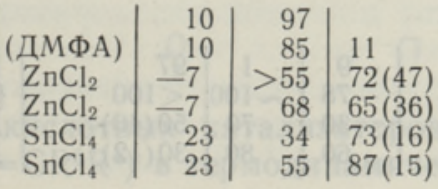




\begin{tabular}{l|l|l|l|l|l|l|l}
\hline 1 & 2 & 3 & 4 & 5 & 6 & 7 \\
\hline
\end{tabular}

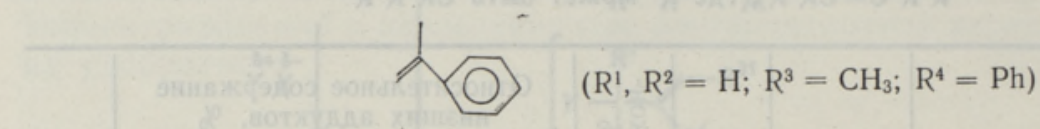

\begin{tabular}{|c|c|c|c|c|c|c|}
\hline $\begin{array}{l}\mathrm{CH}_{3} \mathrm{OCH}_{2} \mathrm{Cl} \\
\mathrm{Ph}_{2} \mathrm{CHCl}\end{array}$ & $\begin{array}{l}\mathrm{ZnCl}_{2} \\
\mathrm{ZnCl}_{2}\end{array}$ & $\begin{array}{l}-78 \\
-78\end{array}$ & $\begin{array}{l}>37 \\
>75\end{array}$ & $\begin{array}{l}100(37) \\
100(75)\end{array}$ & & $\begin{array}{l}{[27]} \\
{[27]}\end{array}$ \\
\hline он же & $\mathrm{ZnCl}_{2}$ & $\begin{array}{l}-78 \\
-78\end{array}$ & $\sim 100$ & 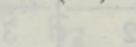 & Л $(47)$ & \\
\hline $\begin{array}{l}\mathrm{PhC}\left(\mathrm{CH}_{3}\right)_{2} \mathrm{Cl} \\
\mathrm{PhCH}\left(\mathrm{CH}_{3}\right) \mathrm{Cl}\end{array}$ & $\begin{array}{l}\mathrm{ZnCl}_{2} \\
\mathrm{ZnCl}_{2}\end{array}$ & $\begin{array}{r}-78 \\
50\end{array}$ & $\begin{array}{l}58 \\
94\end{array}$ & & $\begin{array}{l}\mathrm{B}_{1} 100(58) \\
M 100(80)\end{array}$ & {$[2$} \\
\hline$\left(\mathrm{CH}_{3}\right)_{2} \mathrm{C}=\mathrm{CHC}\left(\mathrm{CH}_{3}\right)_{2} \mathrm{Cl}$ & $\mathrm{ZnCl}_{2}$ & -78 & & & $\mathrm{~b}_{1} 100(29)$ & \\
\hline$\left(\mathrm{CH}_{3}\right)_{2} \mathrm{C}=\mathrm{CHCH}\left(\mathrm{CH}_{3}\right) \mathrm{Cl}$ & $\mathrm{ZnCl}_{2}$ & -78 & 57 & $86(49)$ & $5_{1} 14$ & \\
\hline
\end{tabular}

\rangle$\left(\mathrm{R}^{1}, \mathrm{R}^{2}, \mathrm{R}^{5}=\mathrm{H} ; \mathrm{R}^{3}, \mathrm{R}^{6}, \mathrm{R}^{7}=\mathrm{CH}_{3}\right)$

\begin{tabular}{|c|c|c|c|c|c|}
\hline $\begin{array}{l}\mathrm{CH}_{3} \mathrm{CH}=\mathrm{CHCH}\left(\mathrm{CH}_{3}\right) \mathrm{Cl} \\
\text { OH } \text { Жe } \\
\left(\mathrm{CH}_{3}\right)_{2} \mathrm{C}=\mathrm{CHCH}_{2} \mathrm{Cl} \\
\text { он же }\end{array}$ & $\begin{array}{l}\mathrm{SnCl}_{4} \\
\mathrm{SnCl}_{4} \\
\mathrm{SnCl}_{4} \\
\mathrm{ZnCl}_{2}\end{array}$ & $\begin{array}{l}2 \\
2 \\
2 \\
-78\end{array}$ & $\begin{array}{r}12 \\
66 \\
39 \\
>67\end{array}$ & $\begin{array}{l}46(5) \\
19(9) \\
80(16) \\
90(61)\end{array}$ & $\begin{array}{l}\Gamma_{1} 18 ; \text { Н } 22 ; \text { др } \\
\Gamma_{1} 31 ; \text { H } 33 ; \text { др. } \\
\Gamma_{1} 6 ; \text { K } 12 \\
\text { Б } 10\end{array}$ \\
\hline
\end{tabular}

$\left(\mathrm{R}^{1}, \mathrm{R}^{2}=\mathrm{H} ; \mathrm{R}^{3}, \mathrm{R}^{5}, \mathrm{R}^{6}, \mathrm{R}^{7}=\mathrm{CH}_{3}\right)$

$\mathrm{DCl}$

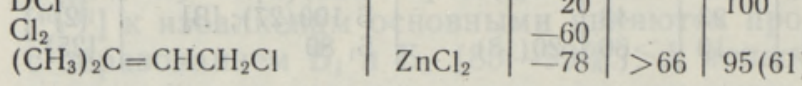

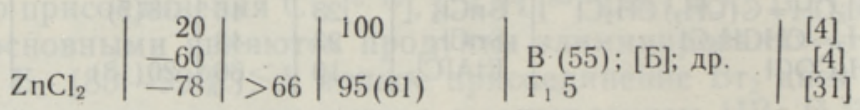

$\Longrightarrow \quad\left(\mathrm{R}^{1}=\mathrm{R}^{7}=\left(\mathrm{CH}_{2}\right)_{3} ; \mathrm{R}^{2}, \mathrm{R}^{3}, \mathrm{R}^{5}, \mathrm{R}^{6}=\mathrm{H}\right)$

$\mathrm{Cl}_{2} \mathrm{CH}_{3} \mathrm{OCH} \mathrm{Ol}_{2} \mathrm{Cl}$ он же

$\left(\mathrm{CH}_{3}\right)_{3} \mathrm{CCl}$

он же

$\mathrm{CH}_{3} \mathrm{COCl}$

\begin{tabular}{|l|r|r|l|l|} 
& 25 & 1 & $\begin{array}{l}80 \\
100 ?(46)\end{array}$ & $\mathrm{Б}_{1} 20$ \\
$\mathrm{ZnCl}_{2}$ & 20 & 40 & $60(10)$ & Б 40 \\
$\mathrm{HgCl}_{2}$ & 20 & $>77$ & & $\Gamma_{1} 79(61)$ \\
$\mathrm{AlCl}_{3}$ & -20 & & & \multicolumn{2}{l}{$14 ; \mathrm{B} 7$} \\
$\mathrm{BiCl}_{3}$ & 97 & 96 & & $\Gamma_{1} 22(20)$ \\
$\mathrm{EtAlCl}_{2}$ & $\sim 10$ & $>89$ & $18(16)$ & $\mathrm{Б}_{3} 24 ; \mathrm{B} 54$ \\
& &
\end{tabular}

$-=-\quad\left(R^{\mathrm{I}}=\mathrm{CH}_{3} ; \mathrm{R}^{2}, \mathrm{R}^{3}, \mathrm{R}^{5}, \mathrm{R}^{6}, \mathrm{R}^{7}=\mathrm{H}\right)$

$\mathrm{Cl}_{2}$

$\mathrm{Ph}_{2} \mathrm{CHCl}$

$\left(\mathrm{CH}_{3}\right)_{3} \mathrm{CCl}$

он же \begin{tabular}{l|r|r|l|l} 
& -9 & 1 & 97 & Б \\
$\mathrm{ZnCl}_{2}$ & -78 & $\sim 100$ & $<100$ & Б \\
$\mathrm{FeCl}_{3}$ & -30 & 70 & $50(40)$ & [ следы] \\
$\mathrm{ZnCl}_{2}$ & 60 & 80 & $30(12)$ & Д 50 \\
\hline Д $30 ;$ Б 40
\end{tabular}
271 


\begin{tabular}{l|l|l|l|l|l|ll|l}
\hline 1 & 2 & 3 & 4 & 5 & 6 & 7 \\
\hline
\end{tabular}

$\left(\mathrm{R}^{1}, \mathrm{R}^{2}, \mathrm{R}^{3}, \mathrm{R}^{5}, \mathrm{R}^{6}=\mathrm{H} ; \mathrm{R}^{7}=\mathrm{C}_{2} \mathrm{H}_{5}\right)$

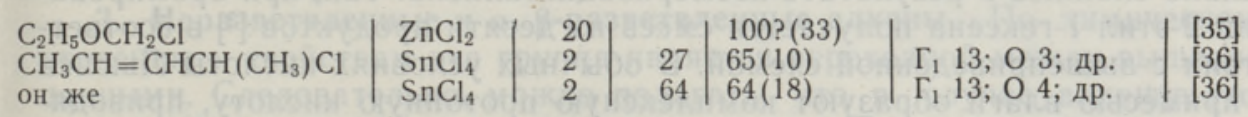

( $\left(\mathrm{R}^{1}, \mathrm{R}^{2}, \mathrm{R}^{3}, \mathrm{R}^{5}=\mathrm{H} ; \mathrm{R}^{6}, \mathrm{R}^{7}=\mathrm{CH}_{3}\right)$

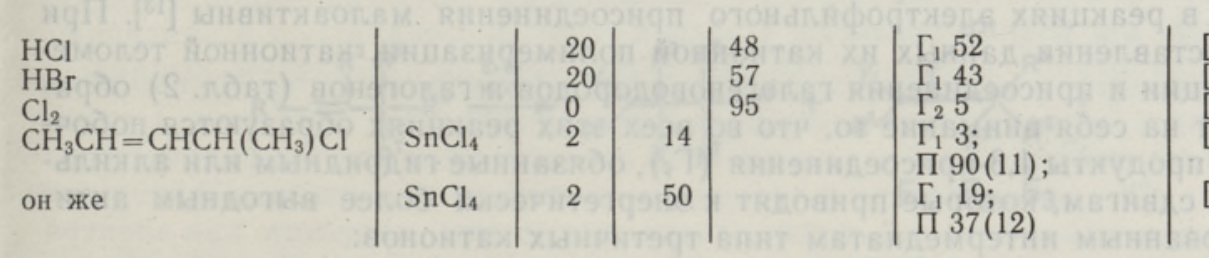

( $\left(\mathrm{R}^{1}, \mathrm{R}^{2}, \mathrm{R}^{3}=\mathrm{H} ; \mathrm{R}^{5}, \mathrm{R}^{6}, \mathrm{R}^{7}=\mathrm{CH}_{3}\right)$

\begin{tabular}{|c|c|c|c|c|c|}
\hline $\begin{array}{l}\mathrm{HCl} \\
\mathrm{Cl}_{2} \\
\mathrm{Cl}_{2} \\
\mathrm{CH}_{3} \mathrm{CH}=\mathrm{CHCH}\left(\mathrm{CH}_{3}\right) \mathrm{Cl}\end{array}$ & $\mathrm{SnCl}_{4}$ & $\begin{array}{r}25 \\
25 \\
-20\end{array}$ & 1 & $\begin{array}{l}17 \\
90 \\
81\end{array}$ & $\begin{array}{l}\Gamma_{1} 83 \\
\mathrm{P} 10 \\
\text { C } 14 \\
\text { соединяется } \\
\text { омеризация } \mathrm{RCl})\end{array}$ \\
\hline
\end{tabular}

* Работы, где использованы малонадежные методы идентификации аддуктов по отношению к примесям, в таблицу не включены или отмечены вопросительным знаком. В квадратных скобках указан продукт, образование которого доказано, но количество не определено. Надо иметь в виду, что в случае побочного перераспределения Н $X$ во многих работах не приняты во внимание либо дегидрогалогенированные продукты $\left(Б_{i}\right)$, либо продукты присоединения $\mathrm{HX}$ (В), хотя, по всей вероятности, эти продукты образуются. Б - общее содержание дегидрогалогенированных продуктов $\left(\mathrm{Б}_{1}, \mathrm{Б}_{2}, \mathrm{Б}_{3}\right)$. Нерегулярные продукты $\mathrm{E}-\mathrm{C}$ следующие:

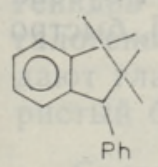

E

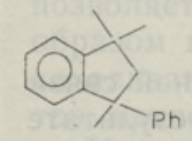

M

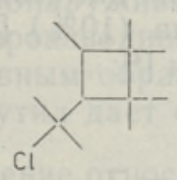

\#

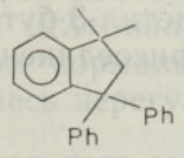

3

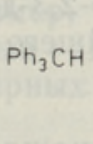

n

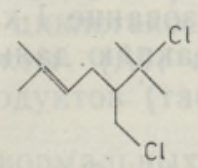

K

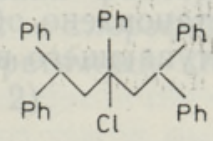

ภ
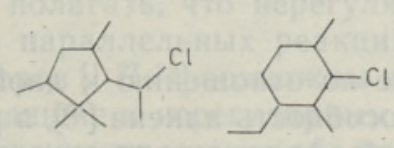

0

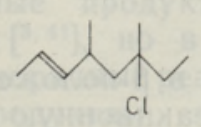

$\Pi$

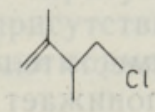

$P$

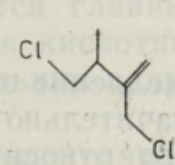

C

Под действием кислотных катализаторов возможна изомеризация изоалкенов-1 $\left(\mathrm{CH}_{2}=\mathrm{CR}^{3} \mathrm{R}^{4}\right)$ в термодинамически более стабильные изо- 
алкены-2 $\left(\mathrm{CH}_{3} \mathrm{R}^{3} \mathrm{C}=\mathrm{CHR}^{41}\right.$ и $\left.\mathrm{CH}_{3} \mathrm{R}^{4} \mathrm{C}=\mathrm{CHR}^{31}\right)\left[{ }^{3,45}\right.$, что может протекать вследствие последовательного протонирования и депротонирования алкена $\left(y^{+}=\mathrm{H}^{+}\right)$. Скорость изомеризации под действием $\mathrm{HBr}$ в несколько раз превышает скорость присоединения $\mathrm{HBr}\left[{ }^{3}\right]$. Это подчеркивает роль конкурирующего направления переноса протона. В случае несимметричных изоалкенов-1 состав образующихся продуктов становится значительно сложнее в результате изомеризации алкена. Так, при бромировании 2-этил-1-гексена получается смесь из десяти продуктов [3] в соответствии с вышеприведенной схемой. В обычных условиях кислоты Льюиса с примесью влаги образуют комплексную протонную кислоту, приводящую к изомеризации. Метиленциклогексан под действием $\mathrm{AlCl}_{3}$ или $\mathrm{ZnCl}_{2}\left[{ }^{45,46}\right]$ дает 1-метилциклогексен, но под действием $\mathrm{C}_{2} \mathrm{H}_{5} \mathrm{AlCl}_{2}$ (который реагирует с водой и создает вполне апротонные условия) изомеризации не происходит [ $\left.{ }^{45}\right]$.

2. $\beta$-Разветвленные алкены, как 3-метил-1-бутен и 3,3-диметил-1-бутен, в реакциях электрофильного присоединения малоактивны $\left[{ }^{13}\right]$. При сопоставлении данных их катионной полимеризации, катионной теломеризации и присоединения галогеноводородов и галогенов (табл. 2) обращает на себя внимание то, что во всех этих реакциях образуются побочные продукты 1,3-присоединения $\left(\Gamma_{i}\right)$, обязанные гидридным или алкильным сдвигам, которые приводят к энергетически более выгодным активированным интермедиатам типа третичных катионов:

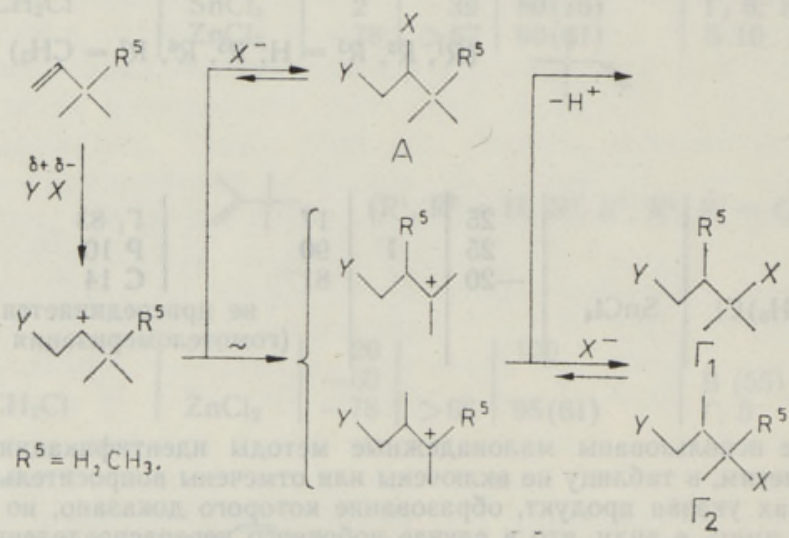

Надо учесть, что эти активированные интермедиаты типа третичных катионов, аналогично вышеизложенному, склонны к реакциям переноса протона, а $\beta$-разветвленные алкены как акцепторы протона малоэффективны. Все же, например, при ионном хлорировании 3,3-диметил-1-бутена установлено образование 1-хлор-2,3-диметил-3-бутена $(10 \%)$ [5], быстро вступающего в реакцию дальнейшего присоединения $\left[{ }^{4}\right]$ :

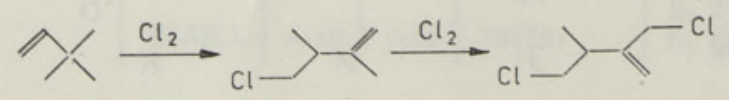

Внедрение заместителей в $\beta$-положение по отношению к двойной связи значительно понижает реакционную способность алкена $\left[{ }^{13}\right]$, в результате чего относительная скорость побочной изомеризации увеличивается (табл. 2).

Есть предположение, что одним из путей образования 1,1- и 1,3-продуктов в случае перемещения атома водорода является отщепление $\mathrm{H} X$ с последовательным присоединением $\left[{ }^{33,34}\right]$. Однако в этом случае должен 
бы образовываться и гидрогалогенид исходного алкена, но об этом в литературе сведений не имеется.

Полимеризация $\beta$-развствленных алкенов 3-метил-1-бутена и 3,3-диметил-1-бутена в присутствии кислот Льюиса приводит главным образом к полимерам, построенным по типу 1,3-присоединения [44].

В $\left[{ }^{1}\right]$ установлена изомеризация 3-метил-1-бутена в 2-метил-1-бутен под действием кислот Льюиса. Объяснить это можно последовательными актами протонирования, гидридного сдвига и депротонирования.

3. Неразветвленные и $\alpha, \beta$-разветвленные алкены. По химическому строению и свойствам эта группа является переходной между вышеописанными. Следовательно, можно полагать, что в случае алкенов этой группы возможно образование как изомерных $\left(\Gamma_{i}\right)$, так и дегидрогалогенированных $\left(Б_{i}\right)$ побочных продуктов наряду с нормальными продуктами (А) при реакциях электрофильного присоединения. Это подтверждают экспериментальные данные (табл. 2):
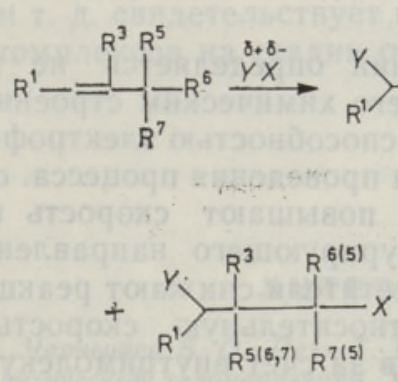

$\Gamma_{1}, \Gamma_{2}, \Gamma_{3}$

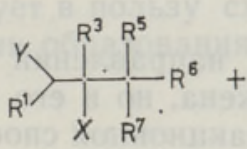

A

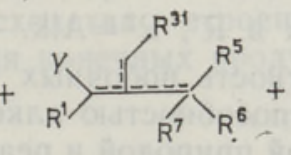

$\bar{E}_{1}, \bar{E}_{2}, \mathrm{E}_{3}$

Пропен и 2-бутен в силу своего строения не могут дать 1,3-продуктов. Особенностью катионной теломеризации галогенопроизводных с 2-алкенами является возможное образование еще и продуктов 1,1-присоединения (Д) (табл. 2), как, например, в случае присоединения трет-бутилхлорида к циклогексену $\left.{ }^{[3}\right]$ или 2-бутену [ $\left.{ }^{34}\right]$. Это понятно, так как в результате внедрения алкильной группы $(y=A \mathrm{lk})$ образуется новый третичный атом углерода, способный к гидридному сдвигу.

Образование побочных продуктов присоединения зависит также от химических свойств реагента $\mathcal{X}$ (табл. 2). Присоединение $\mathrm{HCl}$ или $\mathrm{HBr}$ к алкенам этой группы проходит в общем без изомеризации. При ионном хлорировании наблюдается перераспределение галогеноводорода, причем в широких пределах: например, для 1- и 2-бутена, циклогексена и 2,3,3триметил-1-бутена, соответственно, 3, 2, 20 и $55 \%$ [5]. В случае алкилгалогенидов обнаруживается влияние активности и стерических факторов галогенопроизводного $\mathrm{R} X$ : например, с циклогексеном $\alpha$-хлорэфиры дают главным образом нормальные аддукты (A), а третичный хлористый бутил дает смесь нерегулярных продуктов (табл. 2).

Сравнение относительного содержания нормальных (А) и нерегулярных (Б ${ }_{i}$ или $\Gamma_{i}$ ) аддуктов при различной степени конверсии (табл. 2) позволяет полагать, что нерегулярные продукты образуются главным образом в параллельных реакциях [3,41], но в присутствии кислотных катализаторов $[1,27,29]$ возможны и вторичные реакции нормальных аддуктов, приводящие к нерегулярным продуктам.

Циклические продукты образуются в результате интрамолекулярной атаки по второй кратной связи алкена или по кратной связи, которая внедряется с присоединением непредельного галогенопроизводного $\mathrm{R} X$. При этом новый циклический интермедиат может дать циклические про- 
дукты присоединения или циклические продукты присоединения с дегидрогалогенированием. Легче образуются 5- и 6-членные циклы, но получены даже производные циклобутана (табл. 2). Термодинамические аспекты образования циклобутанов обсуждены в [19].

Вышеизложенное о реакциях электрофильного присоединения к алкенам можно резюмировать следующей схемой:

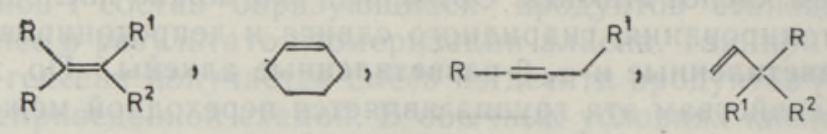

перераспределение галогеноводорода

изомеризация

$\mathrm{R}=\mathrm{H}, \mathrm{Alk}$ и $\mathrm{R}^{1}, \mathrm{R}^{2}=\mathrm{Alk}$.

Вероятность побочных направлений определяется не только реакционной способностью алкена, но и его химическим строением, а также химической природой и реакционной способностью электрофильного реагента $У X$ и катализатора и условиями проведения процесса. $\alpha$-Алкильные заместители у двойной связи алкена повышают скорость как электрофильного присоединения, так и конкурирующего направления переноса $\beta$-протона в алкен. $\beta$-Алкильные заместители снижают реакционную способность алкена, но увеличивают относительную скорость побочного образования 1,3-изомерных продуктов за счет внутримолекулярных гидридных или алкильных сдвигов из $\beta$-положения. Аналогичные побочные направления реакции связаны и с заместителями в $\alpha^{\prime}$-положении, которые являются также $\beta$-заместителями по отношению к катионному центpy $\left(y-\underset{\alpha^{\prime}}{\mathrm{C}}-\stackrel{+}{\mathrm{C}}-\underset{\beta}{\mathrm{C}}\right)$. Например, вышеотмеченное образование 1,1 -аддуктов (Д) при катионной теломеризации $(y X=\mathrm{RCl}) \quad 2$-алкенов $\left[{ }^{33,34}\right]$ и побочное замещение $\alpha^{\prime}$-водорода (с образованием продуктов $Б_{3}$ ) при хлорировании стирола, 1-фенилпропена $[47,48]$ и $\alpha$-галогензамещенных алкенов [49]:

$$
\begin{aligned}
\mathrm{PhCH}= & \mathrm{CHR} \stackrel{\mathrm{Cl}_{2}}{\longrightarrow} \mathrm{PhCH}=\mathrm{CClR}+\mathrm{PhCHClCHClR}_{2} \quad\left(\mathrm{R}=\mathrm{H}, \mathrm{CH}_{3}\right) \\
& \mathrm{CH}_{3} \mathrm{CH}=\mathrm{CClCH}{ }_{2} \mathrm{Cl} \stackrel{\mathrm{Cl}_{2}}{\longrightarrow} \mathrm{CH}_{3} \mathrm{CHClCCl}_{2} \mathrm{CH}_{2} \mathrm{Cl}+ \\
& +\mathrm{CH}_{3} \mathrm{CHClCCl}=\mathrm{CHCl}+\mathrm{CH}_{3} \mathrm{CCl}=\mathrm{CClCH}_{2} \mathrm{Cl}
\end{aligned}
$$

Влияние $\beta$-заместителей по отношению к катионному центру на конкурирующие направления реакции объясняется проявлением электронодонорных свойств атомов водорода и алкильных групп при взаимодействии с катионным центром. Это приводит к перемещению электронов через интермедиаты I или II с двумя положительными центрами, по которым может совершиться атака нуклеофила, в том числе и алкена:
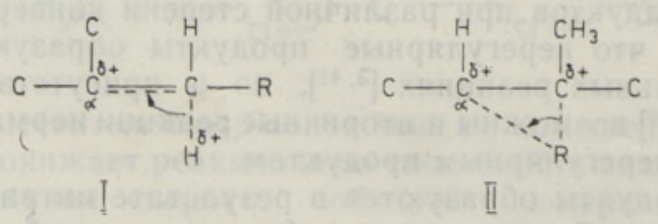

$R=H, A l k$

При этом стерическая напряженность тетразамещенного углеродного атома $\left[{ }^{50,51}\right]$ (образуется из I в случае присоединения нуклеофила к 
$\alpha$-углеродному атому или исчезает в II в результате сдвига группы R) значительно способствует протеканию побочных направлений.

C другой стороны, катионные интермедиаты образуются также при реакциях нуклеофильного замещения путем диссоциирования связи $\mathrm{R}-X$ $(X=\mathrm{Hlg}, \mathrm{OH}, \mathrm{COOR}$ и т. д.). В случае образования при этом интермедиатов типа I или II конкурирующими направлениями при реакциях замещения становятся также, соответственно, отщепление протона или сдвиг водорода или алкильной группы; например, образование побочных продуктов элиминирования или перегруппировки при реакциях гидролиза $\left[{ }^{51}\right]$ :

$$
\begin{aligned}
\left(\mathrm{CH}_{3}\right)_{2} \mathrm{CClC}_{2} \mathrm{H}_{5} \rightarrow \mathrm{I} \rightarrow & \left(\mathrm{CH}_{3}\right)_{2} \mathrm{C}(\mathrm{OH}) \mathrm{C}_{2} \mathrm{H}_{5}+\mathrm{CH}_{2}=\mathrm{C}\left(\mathrm{CH}_{3}\right) \mathrm{C}_{2} \mathrm{H}_{5}+ \\
& +\left(\mathrm{CH}_{3}\right)_{2} \mathrm{C}=\mathrm{CHCH}_{3}, \\
\left(\mathrm{CH}_{3}\right)_{3} \mathrm{CCH}_{2} \mathrm{Cl} \rightarrow \mathrm{II} \rightarrow & \left(\mathrm{CH}_{3}\right)_{2} \mathrm{C}(\mathrm{OH}) \mathrm{CH}_{2} \mathrm{CH}_{3}+\left(\mathrm{CH}_{3}\right)_{2} \mathrm{C}=\mathrm{CHCH}_{3} .
\end{aligned}
$$

Вышеизложенное сходство конкурирующих направлений реакций при катионной полимеризации, теломеризации, галогенировании, гидрогалогенировании и т. д. свидетельствует в пользу сходства в строении активированных комплексов на стадии образования конечных продуктов.

\section{Л ИТ Е Р АТ У РА}

1. Лээтс К. В., Чернышев В. О., Пехк Т. И., Ранг Х. А., Эрм А. Ю. К изучению ионно-каталитической теломеризации. XV. Теломеризация гем.-диалкил- и $\beta$-алкилзамещенных 1-алкенов. - Ж. орг. хим., 1978, 14, № 5, 913-920.

2. Мукс Э. А., Лээтс К. В. K изучению ионно-каталитической теломеризации, XXII. O перераспределении галогеноводорода при теломеризации изоалкенов. - Ж. орг. хим., 1985, 21, № 6, 1177-1810.

3. Wolinsky, J., Novak, R. W., Erikson, K. L. The reaction of bromine with disubstituted terminal olefins. - J. Org. Chem., 1969, 34, N 3, 490-495.

4. Bilke, H., Collin, G., Duschek, Ch., Hoebold, W., Hoehn, R., Prizkow, W., Schmidt, H., Schnurpfiel, D. Elektrophile Additionen an umlagerungsfähige aliphatische Olefine. - J. Prakt. Chem., 1969, 311, N 6, 1037-1057.

5. Poutsma, M. L. Chlorination studies of unsaturated materials in nonpolar media. J. Amer. Chem. Soc., 1965, 87, N 19, 4285-4293.

6. Петров А. А., Генусов М. Л. Ионная теломеризащия. Л., 1968, 9-132.

7. Belluci, G., Bianchini, R., Ambrosetti, R., Ingrosso, G. Comparison of molecular bromine and tribromide ion as brominating reagents. - J. Org. Chem., 1985, 50, N $18,3313-3318$.

8. Сергеев Г. Б., Сергучев Ю. А., Смирнов В. В. Молекулярные комплексы в жидкофазном галогенировании непредельных соединений. - Успехи химии, 1973, 42, № 9, 1545-1573.

9. Смит В. А. Новое в реакциях электрофильного присоединения по двойной связи. Ж. Всес. хим. о-ва, 1977, 22, № 3, 300-314.

10. Schmid, G. H., Garratt, D. G. Electrophilic additions to carbon-carbon double bonds. - In: Chemistry Doub!e-Bonded Functional Groups, 2. Chichester, 1977, 725-912; Schmid, G. H., Gordon, J. W. Evidence for molecular complexes in the mechanism of additions of iodine monochloride to alkenes. - Can. J. Chem., 1984, 62, N 11, 2526-2534.

11. Сергеев Г. Б., Смирнов В. В., Ростовщикова $T$. Н. Гидрохлорирование ненасыщенных соединений, - Успехи химии, 1983, 52, № 3, 455-482.

12. Лээтс К. В. К изучению ионно-каталитической теломеризации. - Ж. орг. хим., 1978,14 , № 4, 686-694; 1982, 18, № 10, 2033-2036.

13. Dubois, J. E., Mouvier, G. Réactivité des composes éthyleniques: réaction de bromation. - Bull. Soc. Chim. France, 1968, N 4, 1426-1435.

14. Bienvenue-Goetz, E., Dubois, J. E. Ethylenic compounds reactivity: bromination. Tetrahedron, 1978, 34, N 13, 2021-2026.

15. Мкрян Г. Г., Акопян С. К., Мартиросян $Г . T$. Жидкофазное хлорирование 1,3-днхлор-2-бутена и 1-хлор-3-метил-2-бутена. - Арм. хим. ж., 1982, 35, № 4 $241-246$.

16. Тищенко Д. В. Аддитивная способность двойной связи при четвертичном углероде. Ж. общ. хим., 1938,8 , № $13,1232$. 
17. Burgin, J., Hearne, G., Rust, F. Derivatives of allylic chlorides. - Ind. Eng. Chem., $1941,33, \mathrm{~N} 3,385-388$.

18. Mayr, H., Pock, R. Relative reactivities of alkenes toward the diphenylmethyl cation. - Tetrahedron Lett., 1983, 24, N 21, 2155-2158.

19. Mayr, H., Klein, H., Kolberg, G. Lewis-Säure-katalysierte Additionen 1,3-Alkylsubstituierter Allylchloride an Alkene. - Chem. Ber., 1984, 117, N 8, 2555-2579.

20. Генусов М. Л., Петров А. А. Теломеризация аллильных хлоридов с олефинами. Ж. общ. хим., 1963, 33, № 9, 2859-2863.

21. Klein, H., Erbe, A., Mayr, H. Kationische Prenylierung von Olefinen. - Angew. Chem. Suppl., 1982, N 1, 105-112.

22. Мещеряков А. П., Эрзютова Е. И., Петров А. Д. Низкотемпературное алкилирование $\alpha$ - и $\beta$-олефинов третичными галондалкилами в присутствии хлористого цинка. Изв. АН СССР. Отд. хим. н., 1956, № 1, 67-73.

23. Мукс Э., Эрм А., Кабрал С., Лээтс К. Продукты хлорирования 2-метил-2-бутена. Изв. АН ЭССР. Хим., 1979, 28, № 1, 46-48.

24. Straus, F., Thiel, W. Anlagerung von Alkylhalogeniden an die Athylenbindung. Liebigs Ann. Chem., 1936, 525, N 2-3, 151-182.

25. Snider, B. B., Jackson, A. C. Use of ethylaluminium dichloride as a catalyst for the Friedel-Crafts acylation of alkenes. - J. Org. Chem., 1982, 47, N 27, 5393-5395.

26. Burgin, J., Engs, W., Groll, H. P. A., Hearne, G. Halogenation of hydrocarbons. Ind. Eng. Chem., 1939, 31, 1413.

27. Mayr, H., Striepe, W. Scope and limitations of aliphatic Friedel-Crafts alkylations. - J. Org. Chem., 1983, 48, N 8, 1159-1165.

28. Капланян Э. Е., Айрапетян Р. Х., Назарян А. А., Мкрян Г. М. Получение 2-алкоксиметил-3-метилбутадиенов-1,3. - Арм. хим. ж., 1975, 28, № 11, 898-902.

29. Ранг Х. А., Чернышев В. О., Пехк Т. Н., Эрм А. Ю., Лээтс К. В. Теломеризащия 2-хлор-транс-3-пентена с 2,3-диметил-1-бутеном. - Ж. орг. хим., 1979, 15, № 4, $686-691$.

30. Лээтс K., Ранг X., Чернышев B., Пехк T. О составе продукта теломеризации 1-хлор3-метил-2-бутена с 2,3-диметил-1-бутеном. - Изв. АН ЭССР. Хим., 1982, 31, № 2, 147-148.

31. Mayr, H., Klein, H., Sippel, E. Synthese von 1,2,3,3,6,6-Hexamethyl-1-Cyclohexen. Chem. Ber., 1983, 116, N 11, 3624-3630.

32. Шихмамедбекова А. З., Мамедов Ф. А. Реакции отщепления в ряду циклогексеновых $\gamma$-галогенэфиров. - Ж. орг. хим., 1968, 4, № 4, 607-610.

33. Schmerling, $L$. Condensation of $t$-butyl chloride with cyclohexene. - J. Amer. Chem. Soc., 1947, 69, N 5, 1121-1125.

34. Schmerling, L., Meisinger, E. E. Condensation of $t$-butyl halides with propene, 1-butene, and 2-butene. - J. Amer. Chem. Soc., 1953, 75, N 24, 6217-6222.

35. Пиинамаззаде Б. Ф. Алкилирование альфа-хлорэфиров с этиленовыми углеводородами. - Тр. Ин-та хим. АН АзССР, 1954, 13, 49-90.

36. Чернышев В. О., Пехк Т. Н., Ранг Х. А., Лээтс К. В. Теломеризация 2-хлор-транс-3пентена с 1-пентеном. - Ж. орг. хим., 1977, 13, № 11, 2300-2304.

37. Pocker, J., Stevens, K. D. Kinetics and mechanism of addition of acids to olefins. J. Amer. Chem. Soc., 1969, 91, N 15, 4205-4209.

38. De la Mare, P. B. D. Electrophilic Halogenation. London, 1976, 64-95.

39. Hedge, S. G., Vogel, M. K., Otiver, M., Wolinsky, J. The reaction of hydrochlorous acid with olefins. A convenient synthesis of allylic chlorides. - Tetrahedron Lett., 1980, 21, N 5, 441-444.

40. Бодриков Н. В., Спиридонова С. В., Смолян 3. С. Электрофильное галогенирование олефинов. $\longrightarrow$ Ж. орг. хим., 1977, 13, № 3, 486-493.

41. Карташов В. Р., Пушкарев В. П., Бодриков И. В., Тишков К. Н. Молекулярные перегруппировки в реакциях присоединения к непредельным соединениям. - Ж. орг. хим., 1971,7 , № $8,1570-1574$.

42. Arnold, R. T., Lee, W. W. The low temperature halogenation of isobutylenes. J. Amer. Chem. Soc., 1953, 75, N 21, 5396-5400.

43. Лээтс K., Мукс Э., Крумм Л. Относительная реакционная способность метилзамещенных производных хлористого аллила при катионной теломеризации с 2 метил-2-бутеном. - Изв. АН ЭССР. Хим., 1985, 34, № 3, 170-175.

44. Кеннеди Дю. Катионная полимернзация олефинов. М., 1978, 86-172.

45. Snider, B. B., Rodini, D. J., Karras, M., Kirk, T. C., Deutsch, E. A., Cordova, R., Price, R. T. Alkylaluminium halides. Lewis acid catalysts which are Bronsted bases. - Tetrahedron, 1981, 37, N 23, 3927-3934.

46. Гаджиев М. М., Шихмамедбекова А. З., Воробьев Л. Н., Мамедов И. М. Исследование реакции присоединения $\alpha$-галогенэфиров к метиленциклоалкенам. - Ж. орг. хим., 1974,10 , № 7, 1368-1375.

47. Fahey, R. C., Schubert, C. Polar addition to olefins. - J. Amer. Chem. Soc., 1965, 87, N 22, $5172-5179$.

48. Negoro, T., Ikeda, Y. Bromochlorination of alkenes with dichlorobromate (1-) -ion. Bull. Chem. Soc. Jap., 1984, 57, N 8, 2111-2115.

49. Мкрян $\Gamma$. Г., Капланян Э. Е., Мкрян $Г, . М$. Об аномальной реакции хлорирования 
этиленовых соединений, содержащих атом хлора у двойной связи. - Ж. орг. хим., 1981,17 , № 8, 1575-1580.

50. Grosjean, D., Mouvier, G., Dubois, J. E. Predominance of steric effects on the reactivity of tetrasubstituted alkenes. - J. Org. Chem., 1976, 41, N 24, 38723876.

51. Brown, H. C., Moritani, J. Steric effects in elimination reactions. - J. Amer. Chem. Soc., 1955, 77, N 13, 3623-3628.

Ннститут химии

Академии наук Әстонской ССР
Поступила в редакцию 6/VI 1986

\section{Elvi $M U K S$}

\section{ELEKTROFIILSED UHINEMISREAKTSIOONID. KONKUREERIVAD REAKTSIOONISUUNAD OLENEVALT ALKEENI EHITUSEST}

Võrdlevalt on käsitletud alkeenide katioonsete ühinemisreaktsioonide, nagu halogeenimine, hüdrohalogeenimine, telomerisatsioon, polümerisatsioon jt. produktide koostist. Konkureerivad reaktsioonisuunad on määratud alkeeni keemilise ehitusega. Kaksiksideme suhtes $\alpha$-alküülasendusrühmad soodustavad halogeenvesiniku ümberpaiknemist produktidest lähtealkeeni, $\beta$-alküülrühmad - isomeersete produktide moodustumist.

\section{Elvi MUKS}

\section{COMPARISON OF ELECTROPHILIC ADDITION REACTIONS. REACTION WAYS DEPENDING ON THE ALKENE STRUCTURE}

The comparison of the products of cationic addition of alkyl halides, hydrogen halides, and halogens, and cationic polymerization has been made. It was shown that the $\alpha$-alkyl substituents at the double bond promote redistribution of hydrogen halide from the products to the starting alkene, while $\beta$-alkyl substituents lead to rearranged products due to hydride or alkyl shifts. 